\title{
REAL-TIME EVALUATION OF ROOM ACOUSTICS USING IFC-BASED VIRTUAL REALITY AND AURALIZATION ENGINES
}

\author{
Simon Swanström Wyke ${ }^{1}$, Kjeld Svidt ${ }^{2}$, Flemming Christensen ${ }^{3}$, Jesper Bendix Sørensen ${ }^{4}$, \\ Torgeir Mithun Fadnes ${ }^{5}$ and Rasmus Lund Jensen ${ }^{6}$
}

\begin{abstract}
Virtual Reality and Auralization are commonly used for separate types of simulation and evaluation in todays' building industry. Combining the two technologies in order to evaluate room acoustics through real time auralization is still a novel approach in the industry. Common practises in designing room acoustics were identified in a case company, and used in the developing of a combined audio-visual system. The case company, additionally, participated in the testing of the system. The system is developed to support dialog between designers and end-users, with no or limited acoustic expertise and to widen the use of virtual reality with auralization.
\end{abstract}

Keywords: Virtual Reality, Auralization, System Development.

\section{INTRODUCTION}

The indoor environment has become an increasingly important topic in the building industry in recent years. This has led to increased research into how room acoustics influences people's performances and how auralization can be used for simulation of room acoustic (Reinten et al., 2017). In this paper, we define Auralization as the process of making an acoustic space audible, thus enabling listening to the space under design. (Kleiner, M.; Dalenback, B-I.; Svensson, 1993; Savioja and Svensson, 2015).

The increased use of 3D models with attached building information (Building Information Modelling, BIM) in the building industry can facilitate the transfer from 3Ddesign models into Virtual Reality (Bille et al., 2014; Wang et al., 2014; Du et al., 2018; Sebastian et al., 2018). Recent years' development of VR and the reduced cost of both VR hardware and software has enabled a wider use of it as an interactive design platform, allowing people to interact within the Virtual Environment (VE) (Svidt and Sørensen, 2012; Petrova et al., 2017; Rasmussen, M.; Gade, A.; Lund Jensen, 2017), and contribute to finding improved design solutions.

BIM based VR however, often has issues such as missing material information and that it can be a time consuming process going from a Computer Aided Design (CAD)

PhD Student, Aalborg University, Department of the Built Environment, Denmark, ssw@build.aau.dk Associate Professor, Aalborg University, Department of the Built Environment, Denmark, svidt@build.aau.dk

Associate Professor, Aalborg University, Department of Electronic Systems, Denmark, fc@es.aau.dk Epiito A/S

COWI A/S

Associate Professor, Aalborg University, Department of the Built Environment, Denmark, rlje@build.aau.dk 
format into VR. This is the case using both proprietary and open source data formats in the data transfer (Du et al., 2018).

Most VR applications used in the building industry, focus mainly on the visual rendering of building geometries (Pelzer, S.; Aspöck, L.; Schröder, D.; Vorländer, 2014; Vorländer, M.; Schröder, D.; Pelzer, S.; Wefers, 2015). The use of sound stimuli can nevertheless augment the visual perception significantly (Schröder, 2011), and other engineering branches using VR have experienced that audio information can be more important in VR applications than the visuals of a Virtual Environment (VE) (Brooks Jr., 1999; Whyte, J.; Nikolic, 2018). Pitt et al., (2005) furthermore emphasise that it would be wrong to assume that VE's must represent full visual realism of the geometry presented in VR to be effective (Pitt, M.; Goyal, S.; Holt, P.; Ritchie, J.; Day, P.; Simmons, J.; Robinson, G.; Russell, 2005; Swanström Wyke, Christensen, et al., 2019).

Adding the room acoustic model to the 3D model of the building's geometry makes it possible to do auralization (Savioja and Svensson, 2015). Combining visualization and audio further makes it possible to attain end- user evaluation early in a design process, get empirical measurements of user's performances, and do iterative user testing (Gould and Lewis, 1985; Kim, Cha and Kim, 2016) not only with respect to the visual and geometric design of a room, but also the acoustic design.

\subsection{Evaluation of room acoustics}

Evaluation of room acoustics mostly occur in acoustically challenging spaces, such as concert halls, train stations, airports and theatres, and traditionally focuses on music perception and communication through speech (Pelzer, S.; Aspöck, L.; Schröder, D.; Vorländer, 2014; Vorländer, M.; Schröder, D.; Pelzer, S.; Wefers, 2015). Savioja and Svennson (2015), however, argue that acoustic traits of educational buildings, public venues and homes are important to evaluate as well.

How the acoustics of a room affect people and their performances depends on what type of room is under consideration, what tasks are performed in the room in addition to the habits of the room user(s) (Haapakangas et al., 2014; Reinten et al., 2017). Including both clients and end-users in the acoustic room evaluation during design, providing a valid perspective towards such dependencies, allowing for better acoustic design.

The sound environment is what influences task performance of people in a room the most, not the acoustic design. The design of the room acoustics, however, influences the sound environment (Reinten et al., 2017), clarifying the importance of focus on room acoustics during building design.

Room acoustics does not only focus on the airborne sound insulation and structural properties. But also structure-born excitation from HVAC, household appliances and electrical equipment, (Vorländer, M.; Schröder, D.; Pelzer, S.; Wefers, 2015) and sound generated by such, distributed in a room via reverberation.

\subsection{Use of Auralization}

Since the beginning of the 1990s, computer simulation of room acoustics has been feasible (Kleiner, M.; Dalenback, B-I.; Svensson, 1993). Before computers were used in this regard, acoustic design had to be based on equations providing the sound field average, or investigations in scale models. However, due to the sensitive perception of humans, more specific investigations are needed in order to match the desired performance of the client and end- user(s) of a room (Pelzer, S.; Aspöck, L.; Schröder, D.; Vorländer, 2014). 
Some acoustic problems can be solved by acoustic engineers solely based on calculations and analysis. Sometimes however, the process of particular auditory perception is not finally understood. In such cases auralization can contribute to finding a solution (Pelzer, S.; Aspöck, L.; Schröder, D.; Vorländer, 2014).

One of the important phenomena in room acoustics is reverberation (Pelzer, S.; Aspöck, L.; Schröder, D.; Vorländer, 2014; Xia et al., 2015). Prediction of reverberation can be done rather precisely by using the room volume and the average absorption coefficients for each surface (Kuttruff, 2000; Pelzer, S.; Aspöck, L.; Schröder, D.; Vorländer, 2014).

Both 3D models with building information attached and databases of absorption coefficients exist in most engineering companies. We therefore investigated how data are generated and used, in a case study, to design a VR with Auralization (VRA) system for the building design process, based on common practise in an engineering company with branch offices in both Denmark and Norway. The company participated in the case study inquiry, which lead to the iterative development and tests of the VRA system, presented in this paper.

\section{METHODOLOGY}

\subsection{Empirical inquiry}

Multiple employees from the Danish and Norwegian branch offices of the company were interviewed, to investigate current design processes in the company, and attain understanding of how data is transferred within their project organisation.

Empirical data were acquired through the contextual design methodology, as described by Beyer and Holtzblatt (1997).

\subsection{Test of Virtual Reality with Auralization system}

A VRA system was developed, based on the Unity 3D engine, Epiito software and AM3D spatial audio software (Europe Goertek, 2019) as shown in figure 1.

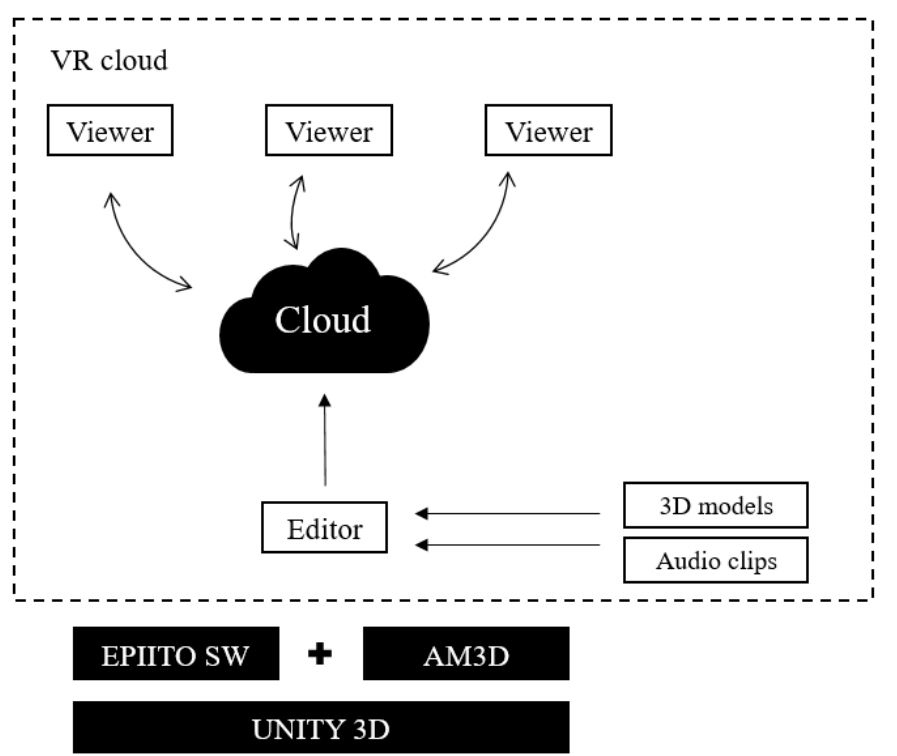

Figure 1 Flow model describing the system context of VRA, in this scenario the AM3D auralization engine is used. 
The VRA system has a distinct focus on user interaction, visual presentation of building geometries and auralization. It furthermore reads the Industry Foundation Classes (.ifc) format, allowing system interoperability with multiple building and construction-modelling applications used in the building design industry, in a nonvendor specific format.

Acoustic rooms in VR are generated from IFC-spaces and anechoic sound-sources can be placed in the acoustic space, allowing for auralization.

The game engine Unity allows for at least two different auralization engines Resonance Audio and AM3D Spatial audio. Both engines allow positioning of sound sources and simulation of reverberation based on room dimensions and material properties. Both the AM3D and Resonance auralization engines were tested in this study.

Based on initial tests of VR with Auralization, test scenarios were selected, to assess realism and functionality of the VR- auralization system. As the perception of sound differentiates from person to person, and tends to be sensitive (Vorländer, M.; Schröder, D.; Pelzer, S.; Wefers, 2015), the tests were based on how the test persons perceived the room acoustics in VRA.

Sound from electronic equipment, household appliances and a ventilation system were recorded in an anechoic room, to eliminate influence from reverberation, to make the recordings controllable by the auralization engine (Swanström Wyke, Christensen, et al., 2019; Swanström Wyke, Sørensen, et al., 2019). The audio clips were recorded to initiate the build of a sound database for use in Virtual Reality with Auralization (VRA) systems. This database is still in the early stages of development, but could potentially aid the industry, allowing firms already using VR technology to also include auralization.

The anechoic audio clips in .wav format were inserted into VR using the AM3D suite or the Resonance Audio auralization engine. The absorption coefficients of surfaces the sound clips were played from are manually adjusted based on the materials of the room surfaces and the measured reverberation. The auralization engines only allow specification of one overall absorption coefficient per surface.

Both end-users, researchers and system developers, engaged in informal listening tests and informal user experience tests.

All test scenarios were presented in VR through Oculus Rift VC1 and Oculus Quest head mounted display (HMD) and Seenheiser PC 363 D as well as Bose QC35 ii headphones as listening device, calibrated using a sound-level calibration box, shown in figure 2, developed as part of the system development (Swanström Wyke, Sørensen, et al., 2019).

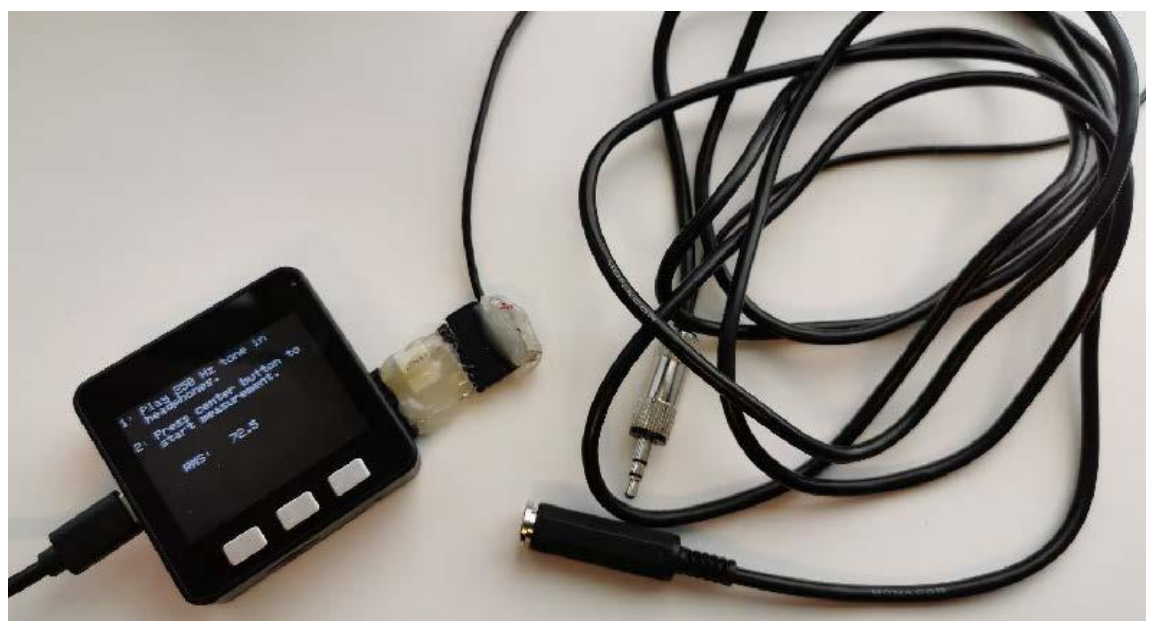

Figure 2 Calibration box designed for calibration and level adjustment of the headphones used with the system 
As the two auralization engines used with the VRA system do not support surface sound-sources, but only allows use of point sources, the tests were performed to find a sound-source placement technique providing the experience of an equal distribution of sound amongst sources in a room.

In the sound distribution test, five respondents tested the possibility of simulating an entire surface, e.g. a window or a wall as a sound source by means of a limited number of point sources. The respondents were exposed to a test scenario with 21 sound sources with and without windows and 7 sound sources, placed in a grid on a wall surface as shown in figure 3. The respondents then walked by the wall, and around in the area in front of the sound sources in order to evaluate the degree of realism of the acoustic room presented.

The second sound test included another scenario with a single sound source, designed to follow the movement of the respondent's avatar. Like in the other tests, respondents again moved around the test area, experiencing the acoustic room presented through VRA. This time however, with the sound source following the avatar. This allowed for an apparently even distribution of sound, as the avatar's movement did not lead to different sound sources being prominent experienced when moving around in the test area.

In the VRA system, a maximum of 512 sound sources can be placed in the VE. This number is per avatar immersed into VR.

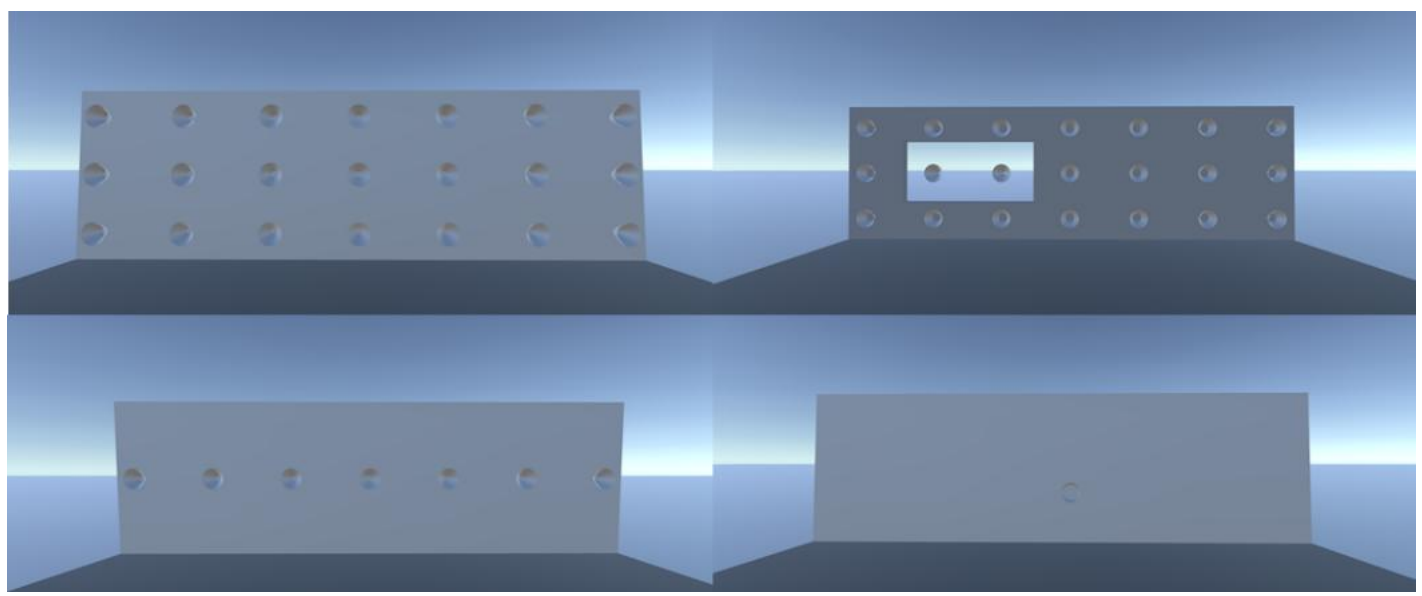

Figure 3 The four sound distribution test-scenarios

\subsection{End-user test and presentation}

In the end-user, test and presentation 17 respondents participated in informal user experience tests. The scenario presented, was a lecture room at the Department of the Built Environment at Aalborg University, and included sound sources placed in four locations in the room. The scenario was used in earlier test-sessions as well, allowing some of the respondents whom had participated in earlier testing, to compare functionality, realism and intuitiveness of the system.

The four sound sources placed in the test-scenario were:

1. Speech playing from a non-playable character, placed in the VE.

2. Sound from electronic equipment.

3. Sound from construction work from a window.

4. Sound from neighbouring room through an open door. 
The scenarios were presented to the respondents in two versions. One with an open window in the room and one with the window closed.

\section{RESUlTS}

\subsection{Case company inquiry}

In the company participating in the case study, acoustic designing is typically a collaboration between architects and acoustic engineers (figure 4). The design process they conduct is iterative, and involves evaluation of 2-3 scenarios with respect to acoustic room design. The focus on acoustics is, however, dependent on the building type. Concert halls, theatres and other sound sensitive buildings are treated with more concern than e.g. office buildings and housing estates, as is also common practise in the industry (Pelzer, S.; Aspöck, L.; Schröder, D.; Vorländer, 2014; Vorländer, M.; Schröder, D.; Pelzer, S.; Wefers, 2015).

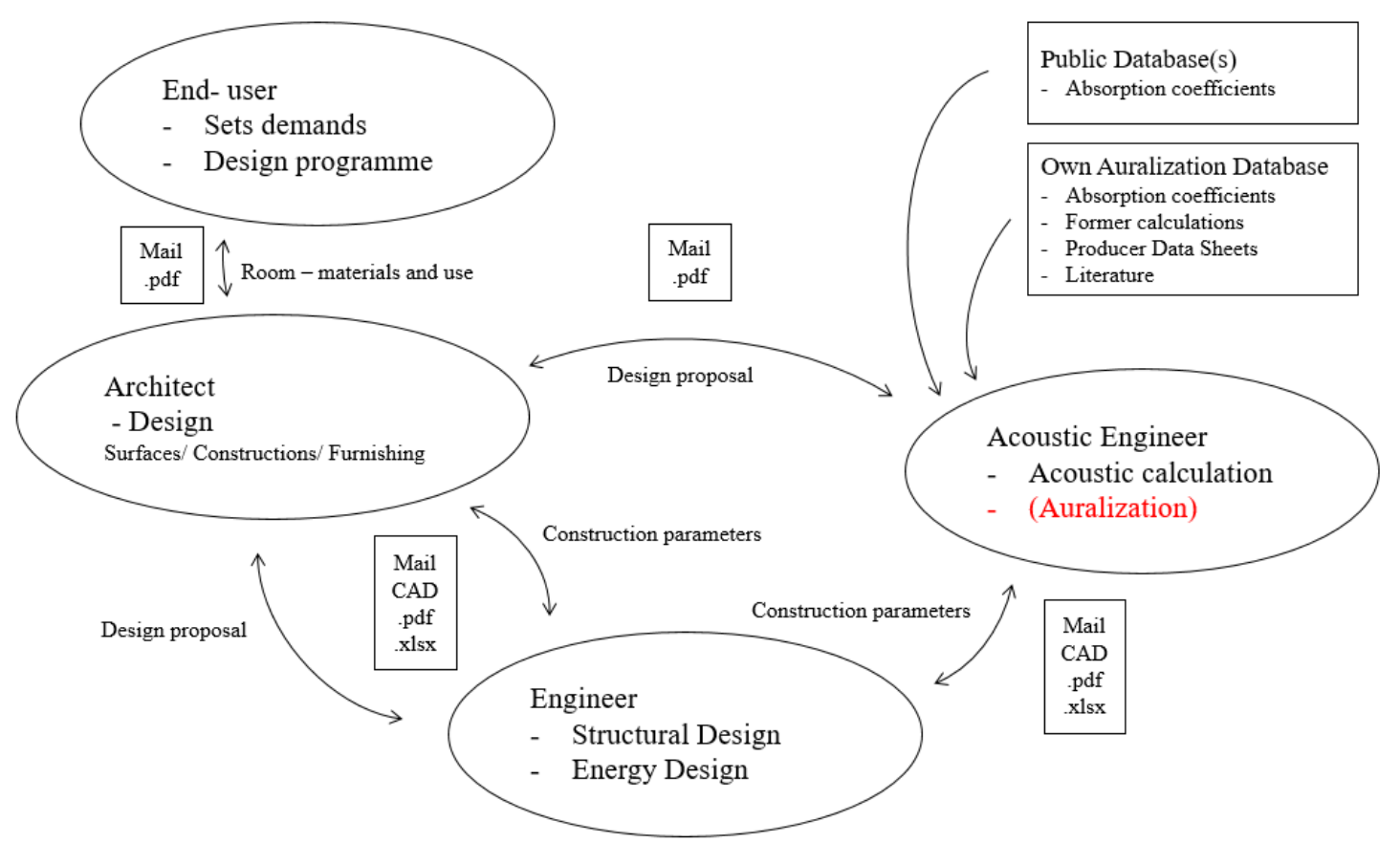

Figure 4 Flow model of the current design process with respect to acoustic design, in the case company.

In the case-company, most building-design projects are modelled in $3 \mathrm{D}$ and data are primarily exchanged in the proprietary (Revit) format .rvt. The .ifc format is also used in the company, mainly in the Norwegian branch in which the use is standard procedure. The format is also occasionally used in the Danish branch office.

The company primarily relies on the building regulation, when designing room acoustics. Clients, however, sometimes demand a better acoustic environment than the building regulations define. Such increased demands are formulated in the design brief of a project. The design brief is not always present in Danish design projects, it is, however, mandatory on projects in Norway. According to the respondents, demands set by clients rarely extent the building regulation's demands to acoustic design in Norway, but occasionally happens on projects in Denmark. 
In acoustic design projects, time and money often limit the depth in which acoustic evaluations of rooms are performed. The company, therefore, primarily focusses on the most sensitive rooms, whilst keeping most of the acoustic evaluation on building level.

With respect to technical installations in a building's design, selection of a design proposal is mainly based on dialog between the architect developing proposals, and the acoustic engineers calculating the effect of said design.

Dialog, combined with results from analysis and calculation tools, are currently the key tool the design team uses to evaluate and find the optimal acoustic design solutions. The dialog and general communication between parties in the company consist of multiple exchange formats, going from mail, PDF, CAD formats (.ifc, .rvt, .dwg) to .xlsx and .docx.

Acoustic calculations of reverberation are based on absorption coefficients found in the company's own database which consist of calculations done on previous projects, literature and supplier data sheets. In some occasions, the company also uses public databases.

Sometimes, however rarely, auralization is used by the company, allowing the design team, client(s) and end-user(s) to listen to the proposed or selected acoustic solutions. The auralization currently used in the company, is nevertheless without visual supplement.

During the interviews, the respondents recounted that real time Virtual Reality with auralization could be an aid in explaining design options to clients and end-users and support the communication between parties on a project. A notion the respondents also noted during earlier systems tests (Swanström Wyke, Sørensen, et al., 2019).

User feedback is often relevant in design projects for the company, as surface materials demanded by the client or end- users, affects the acoustic performance of a room. As much of the material selections are also based on the visual preferences of clients and users, a system supporting auralization must also include the visual link. The respondents did not rate the realism of the visualization in VR, as important, as the realism of the auralization during testing.

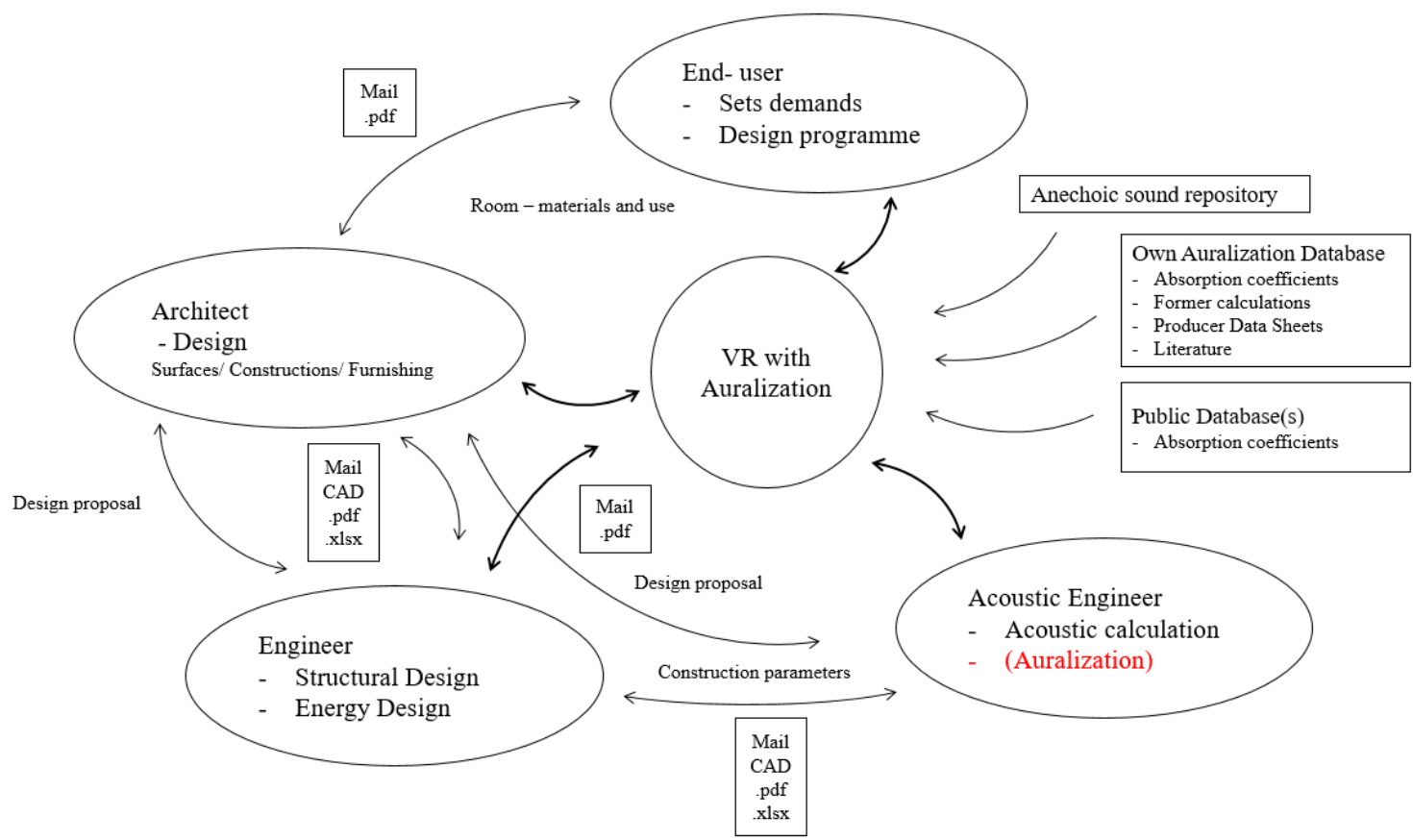

Figure 5 Exchange of information using VR with Auralization as the centre of communication with respect to room acoustics. 
Finally, the respondents not $1 / 2 \mathrm{ed}$ that the a VR based system can also work as the centre of communication on a project (figure 5), and allow for better evaluation and use of building models on a project, not limited to the acoustic preferences, creating indirect benefits through the use of the system.

\subsection{System tests}

The VRA system was tested multiple times during its development. The tests facilitated an iterative design process of the system, allowing end-users, researchers and developers to monitor the evolution of the system. Figure 6 shows a developer introducing and instructing a respondent in how to use system.

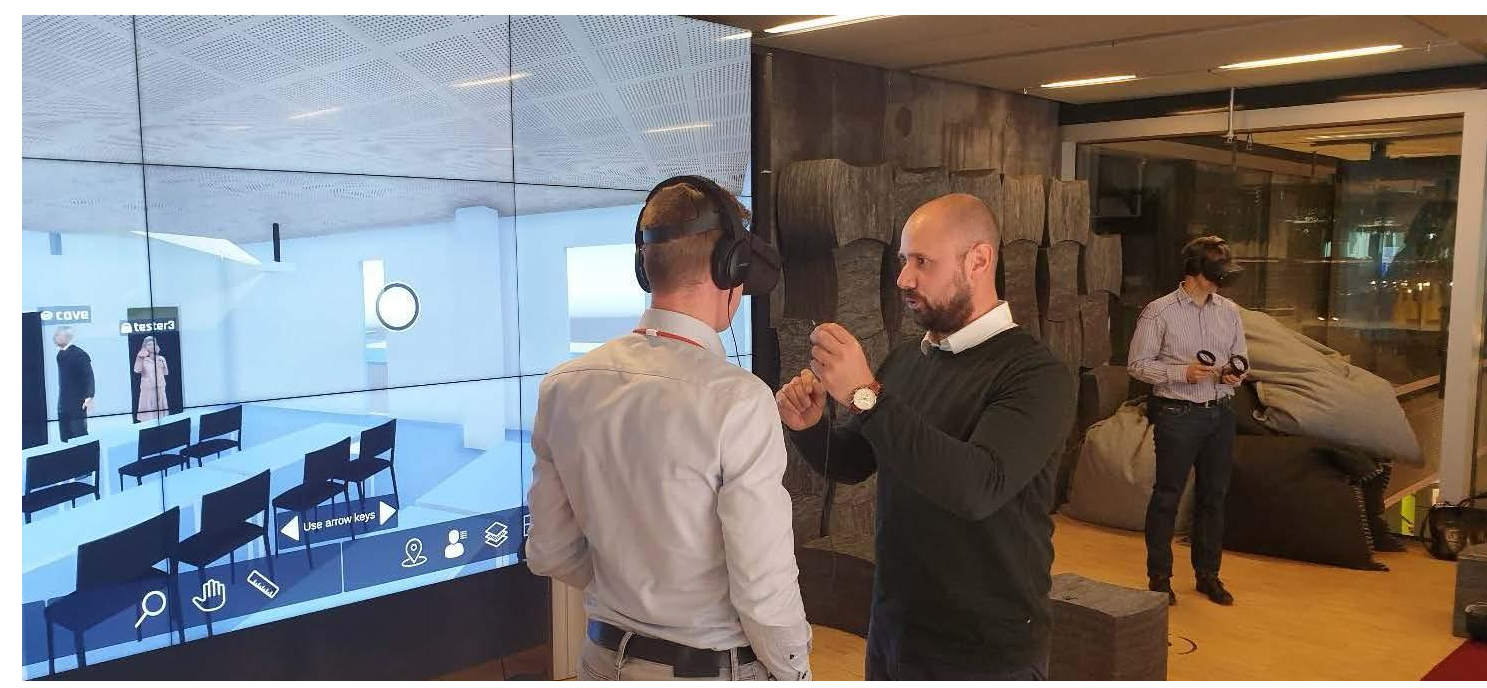

Figure 6 Developer introducing use of head-mounted display and controllers to respondent.

In the sound distribution test, the single sound source solution, which followed the avatar's movements in VR, proved to be the most feasible solution for the VRA system, as sound was experiences as evenly distributed when the test persons moved around in the test area. The single source solution will additionally be an easier solution to automate, as only one source needs to be controlled. Only having one source playing will furthermore result in shorter loading time when opening or loading in a VRA.

In scenarios with multiple sound-sources placed in a fixed grid on a surface, the test persons experienced an unequal distribution of sound from the surface. This allowed the respondents to be able to differentiate the sound sources from each other, instead of experiencing an evenly distributed sound. Such solutions were, therefore, not selected for the further development and testing.

The end-user test and presentation resulted in positive reactions by the test persons. The test persons, however, pointed out some concerns.

One of the main concerns with respect to use of the system was the process of converting computer aided design (CAD) files into VR in a feasible way. The converting of $\mathrm{CAD}$ should according to the test persons not result in an increased workload, but be easy and intuitive to do.

Another issue the respondents addressed was ensuring the quality of auralization when moving from one virtual room to another, as sound sources muted promptly in the test-model when test-persons were moving from one room to another. This limited the 
realism of how sound-transfer between rooms was experienced in the system by the respondents, when compared to how sound-transfer is experienced in the real world.

Experiencing auralization whilst at the same time seeing the visual surroundings of the sound sources, made it possible to evaluate room acoustic of the test scenario, in a tangible fashion, indicated by the test persons. When sound is emanating from a transmission through a wall or other building elements, ensuring an equal distribution of sound in the VRA system was a primary concern of the test persons.

The test further revealed that the respondents found the system to be realistic and accurate, and well suited to implement in the case-company.

In summary, the respondents requested further development of:

- A solution for communication between users in a multi-user setting, in the virtual environment.

- Improved possibilities of handling sound from adjacent rooms.

- Alignment of user-interface with related tools.

- Direct connection between the VR with Auralization system and BIM-authoring tools.

\section{DISCUSSION}

\subsection{The IFC-based Virtual Reality with Auralization}

The system VRA system is designed to allow real-time evaluation of room acoustics, by acoustic non-experts. The developed system makes it possible to generate acoustic spaces based on the IFC code automatically, by pressing a button in the VRA user interface. This makes it easy to go from CAD into VR. It, nevertheless, require the case-company to include IFC in its standard data exchange procedure on design projects.

The sound source mechanism used in the system, has a maximum number of 512 sound sources. The sound sources are loaded into the system based on the distance between avatar and the sound source, reducing the computational capacity needed to run the system.

The interviews revealed that auralization is already used in room acoustic design, in some rare occasions in the company. The respondents were eager to use Virtual Reality with Auralization, allowing designers, clients and end-users, and implementing it as a supplement to the acoustic calculations already performed in the company during building most designs.

In most of the projects designed by the company, building geometries are modelled in Autodesk Revit. This allows them to both visually program the building components and include properties including acoustic parameters usable for an automated VRA generation process.

As 3D models are already being utilized as part of the case company's current work processes, the only matter to address regarding VR is how to export the 3D model with needed parameters and values, into a VR compatible format, in this case ifc.

The use of .ifc in the case- company is, however, not a de-facto standard in al branch offices. This is a challenge in implementation of the VRA system in the company, as the 3D model import in the VRA system is based on the ifc format.

Another issue the company faces with respect to the use of their design models for VRA, is ensuring the needed level of development of geometry and information content of the model, to generate a realistic VE 


\subsection{Cost involved with use of VRA}

There are costs associated with both developing, implementing and using VR with Auralization.

In order to use VR, both head mounted display (HMD); headphones in a good quality and a relatively powerful computer are needed, unless Oculus Quest is used. The cost of hardware is approximately 1.200 to $2000 €$. This cost, however, seems small compared to cost of changing both procedures and mind-sets in the case company, involved with implementing the VRA system.

The empirical inquiry in the case company revealed that ifc is not always the format used to exchange 3D models in their design projects. As the VRA system is based on 3D model import in the ifc format the building model exchange processes in the case company must therefore be updated. This needs to include demands describing the level of development of models exchanged in the ifc format and making the use of ifc a common practise.

Anechoic recordings are not easily accessible and must therefore be available before auralization can become common practice. This process can be costly, as the recording of sounds in an anechoic room or chamber both takes time and demands expert knowledge.

\section{CONCLUSION}

This paper presented an overview over common practises in the building industry with respect to room acoustics, based on interviews performed in a case company. Through a combined audio-visual engine, Auralization engines controlled and played the anechoic sound in the system, allowing respondents to listen to design scenarios, providing a better foundation for decision making with respect to room acoustics.

Multiple informal experience tests in VR with Auralization revealed that the ability to combine experiencing visual and audibly realistic visualisations gave a more tangible basis for selection of acoustic design solutions, than the calculations made and presented in writing or through 3D models.

Real-time evaluation of room acoustic is feasible through use of the Virtual Reality with Auralization system presented in this paper, using IFC-based Virtual Reality and Auralization engines. Further research is, however needed, regarding use of the system in multiple companies, in order to conclude finally on the systems' accuracy and realism.

\section{ACKNOWLEDGEMENT}

We would like to extend our gratitude to the COWI foundation for financing parts of this research. Acknowledgement is also extended to Clemen Boje Larsen from Goertek Europe with assistance regarding the AM3D software suite.

\section{REFERENCES}

Beyer, H. and Holtzblatt, K. (1997) Contextual Design: Defining Costumer-Centered Systems. San Francisco, CA, USA: Morgan Kaufmann Publishers Inc.

Bille, R. et al. (2014) 'Extending Building Information Models into Game Engines', Proceedings of the 2014 Conference on Interactive Entertainment - IE2014, pp. 1-8. doi: $10.1145 / 2677758.2677764$. 
Brooks Jr., F. P. (1999) 'What's Real About Virtual Reality?', IEEE Computer Graphics and Applications, 19(6), pp. 16-27. doi: 10.1109/38.799723.

$\mathrm{Du}$, J. et al. (2018) 'Zero latency: Real-time synchronization of BIM data in virtual reality for collaborative decision-making', Automation in Construction. Elsevier, 85(October 2017), pp. 51-64. doi: 10.1016/j.autcon.2017.10.009.

Europe Goertek (2019) AM3D Software Suite. Available at: http://goertek.eu/researchdevelopment/audio-dsp-algorithms/am3d-software-suite/ (Accessed: 30 April 2019).

Gould, J. D. and Lewis, C. (1985) 'Designing for usability: key principles and what designers think', Communications of the ACM, 28(3), pp. 300-311. doi: 10.1145/3166.3170.

Haapakangas, A. et al. (2014) 'Effects of unattended speech on performance and subjective distraction: The role of acoustic design in open-plan offices', Applied Acoustics. Elsevier Ltd, 86, pp. 1-16. doi: 10.1016/j.apacoust.2014.04.018.

Kim, T. W., Cha, S. H. and Kim, Y. (2016) 'A framework for evaluating user involvement methods in architectural, engineering, and construction projects', Architectural Science Review, 59(2), pp. 136-147. doi: 10.1080/00038628.2015.1008397.

Kleiner, M.; Dalenback, B-I.; Svensson, P. (1993) 'Auralization - an overview', AES: Journal of the Audio Engineering Society, 41(11), pp. 861-875.

Kuttruff, H. (2000) Room Acoustics. Fourth. 11 New Fetter Lane, London EC4P 4EE: Spon Press is an imprint of the Taylor \& Francis Group.

Pelzer, S.; Aspöck, L.; Schröder, D.; Vorländer, M. (2014) 'Integrating Real-Time Room Acoustics Simulation into a CAD Modeling Software to Enhance the Architectural Design Process', Buildings, 4(2), pp. 113-138. doi: 10.3390/buildings4020113.

Petrova, E. et al. (2017) 'Integrating Virtual Reality and BIM for End-User Involvement in Design: A Case Study', in Lean and Computing in Construction Congress Volume 1: Proceedings of the Joint Conference on Computing in Construction. Edinburgh: Heriot-Watt University, pp. 699-706. doi: 10.24928/JC3-2017/0266.

Pitt, M.; Goyal, S.; Holt, P.; Ritchie, J.; Day, P.; Simmons, J.; Robinson, G.; Russell, G. (2005) 'An innovative approach to facilities management in the workplace design brief', Facilities. Edited by E. Finch, 23(7/8), pp. 343-355. doi: 10.1108/02632770510600290.

Rasmussen, M.; Gade, A.; Lund Jensen, R. (2017) 'Bridging the Gap between Actors and Digital tools in a Knotworking Design Process', When Social Science meets BIM and LEAN (Vol. 1, Chapter 5, pp. 3), (January), pp. 1-7.

Reinten, J. et al. (2017) 'The indoor sound environment and human task performance: A literature review on the role of room acoustics', Building and Environment. Elsevier Ltd, 123, pp. 315-332. doi: 10.1016/j.buildenv.2017.07.005.

Savioja, L. and Svensson, U. P. (2015) 'Overview of geometrical room acoustic modeling techniques', The Journal of the Acoustical Society of America, 138(2), pp. 708-730. doi: 10.1121/1.4926438.

Schröder, D. (2011) Auralization of Interactive Virtual Environments. Edited by P. D. rer. nat. M. Vorländer. Köln: Logos Verlag Berlin GmbH. Available at: http://publications.rwth-aachen.de/record/50580/files/3875.pdf.

Sebastian, R. et al. (2018) 'Connecting the Knowhow of Design, Production and Construction Professionals through Mixed Reality to Overcome Building's Performance Gaps', Proceedings, 2(15), p. 1153. doi: 10.3390/proceedings2151153.

Svidt, K. and Sørensen, J. B. (2012) 'Development of a Virtual Reality Solution for End User Involvement in Interior Design', eCAADe: Conferences, 2, pp. 541-546. 
Swanström Wyke, S. C., Sørensen, B., et al. (2019) Real-time Evaluation of Room Acoustics using IFC-based Virtual Reality and Auralization Engines Documentation Report. Aalborg.

Swanström Wyke, S. C., Christensen, F., et al. (2019) 'Realistic Real Time Simulation of Room Acoustics using Virtual Reality with Auralization', in Steinø, N. and Kraus, M. (eds) eCAADe RIS 2019. Aalborg University Press., pp. 153-158.

Vorländer, M.; Schröder, D.; Pelzer, S.; Wefers, F. . (2015) 'Virtual reality for architectural acoustics', Journal of Building Performance Simulation, 8(1), pp. 15-25. doi: 10.1080/19401493.2014.888594.

Wang, J. et al. (2014) 'Integrating BIM and augmented reality for interactive architectural visualisation', Construction Innovation, 14(4), pp. 453-476. doi: 10.1108/CI-03-2014-0019.

Whyte, J.; Nikolic, D. . (2018) Virtual reality and the built environment. 2nd edn. London, United Kingdom: Taylor \& Francis Group.

Xia, R. et al. (2015) 'A Hybrid Approach for Reverberation Simulation', IEICE Transactions on Fundamentals of Electronics, Communications and Computer Sciences, E98.A(10), pp. 2101-2108. doi: 10.1587/transfun.E98.A.2101. 